\title{
Behaviour affects local-scale distributions of Antarctic krill around South Georgia
}

\author{
Katherine A. Cresswell ${ }^{1,3, *}$, Geraint A. Tarling ${ }^{1}$, Michael T. Burrows ${ }^{2}$ \\ ${ }^{1}$ British Antarctic Survey, Natural Environmental Research Council, High Cross, Madingley Road, Cambridge CB3 0ET, UK \\ ${ }^{2}$ Scottish Association for Marine Science, Dunstaffnage Marine Laboratory, Oban, Argyll PA37 1QA, UK \\ ${ }^{3}$ Present address: Department of Applied Mathematics and Statistics, Jack Baskin School of Engineering, \\ University of California, Santa Cruz, California 95064, USA
}

\begin{abstract}
Antarctic krill Euphausia superba are key to most Antarctic ecosystems, particularly at South Georgia, where penguins and seals rely on them for their breeding success each summer. Changes in krill behaviour and local-scale distribution during this time can have large consequences for these predators; however, we currently have little understanding of the behaviour of Antarctic krill in response to changing conditions of predation and food. We used a stochastic dynamic programming model to investigate the behaviour of krill within a region close to South Georgia that is known to be heavily foraged by penguins and seals. In the model, krill responded to changing conditions by adjusting their depth, density of swarm and swimming behaviour. We have shown the optimal behaviour of krill in 3 biologically distinct regions: the on-shelf region, shelf-break region and off-shelf region. We predict significantly higher concentrations of krill will result at the shelf-break region from krill choosing to swim slower and turn more often in a favourable zone. In addition, we predict a diel pattern in swarm density in most conditions of the model, with small krill generally forming lower density swarms than large krill, particularly on-shelf. This work is the first prediction of the effects of krill swarming and swimming behaviour on local-scale distribution.
\end{abstract}

KEY WORDS: Euphausia superba $\cdot$ Behaviour $\cdot$ DVM $\cdot$ Swarming $\cdot$ SDP $\cdot$ Advection $\cdot$ Stochastic dynamic programming $\cdot$ Mortality

Resale or republication not permitted without written consent of the publisher

\section{INTRODUCTION}

Antarctic krill Euphausia superba are of central importance in Antarctic ecosystems (Hamner \& Hamner 2000). This is particularly the case in the region of South Georgia, where they comprise over half the overall zooplankton biomass (Atkinson et al. 2001). In this region, productivity (in terms of both phytoplankton and zooplankton) far exceeds that elsewhere in the Southern Ocean, with krill the major link between primary production and higher trophic levels (Atkinson et al. 2001, Hofmann \& Murphy 2004, Zhou \& Dorland 2004). Large colonies of seals and seabirds depend on krill for their breeding success at South Georgia each summer (Croxall et al. 1999, Atkinson et al. 2001). The recent establishment of a krill fishery in the region has also increased local demand on krill (Everson \& Goss 1991, Mangel \& Switzer 1998, Atkinson et al. 2001). The summer is a critical time of year for krill, particularly in terms of the demand for energy to fuel growth and reproduction (Quetin et al. 1994, Hofmann \& Lascara 2000). Behaviour plays an important role in allowing krill to balance the conflicting demands of maintaining a high energy-intake, while minimising risk to predation.

Krill migrate vertically in the water column (Godlewska 1996); they form swarms or aggregations of varying size and density (Marr 1962); they can travel long distances with currents (Hofmann \& Murphy 2004) and may perform seasonal, directed migrations (Nicol 2006). While we understand that changing conditions, such as phytoplankton levels, predation levels 
and current velocities, affect the outcome of these behaviours, our understanding of each is far from complete.

Diel vertical migration of zooplankton (DVM) was first reported around 190 yr ago (Cuvier 1817) and represents the biggest migration, in terms of biomass, on the planet (Godlewska 1996, Hays 2003). The mechanism for DVM is most likely a classic trade-off between minimising predation risk and maximising food intake, with both decreasing with increasing depth (Iwasa 1982, De Robertis 2002, Burrows \& Tarling 2004). In the classic pattern of DVM, zooplankton occupy the upper food-rich waters at night, when predation risk from visual predators is lower, and the deeper foodpoor waters during the day, when predation risk is higher. However, the observed pattern of krill migration in the field is not always so straightforward, particularly in the region of South Georgia where even the reverse pattern of DVM has occasionally been observed (Kalinowski 1978, Godlewska 1996).

Swarming or schooling affects the density of krill in the water column, which, in turn, affects the encounter rate with predators. It has long been established that krill form dense swarms and that the size and density of swarms can modify the local environment (Marr 1962, Mangel \& Nicol 2000). While many authors agree that a variety of krill aggregation types are possible and that understanding swarming is vital, we currently have little information on the underlying mechanisms. As with DVM, there are costs and benefits to swarming. Proposed benefits include reduced predation through group-avoidance strategies, and evasion and dilution factors once an attack is launched (O'Brien 1987, Ritz 2000). An additional benefit is reduced energy usage through the hydrodynamic advantages of swimming alongside neighbours (Ritz 2000), although there is little experimental evidence concerning krill to support this. The primary cost of swarming is reduced ingestion due to intraspecific competition for food, although swarming can also increase the potential to find food over a greater range of distance (Morris et al. 1983, Hamner \& Hamner 2000, Ritz 2000). Despite the apparent costs and benefits of swarming, the difficulties of studying swarming have meant that there has been little experimental consideration of these parameters. Krill behave very differently in the laboratory than in the ocean; in the former they behave more as individuals than as a school (Strand \& Hamner 1990, Swadling et al. 2005). The use of a model to represent the costs and benefits of swarming may therefore lead to novel insights into the factors affecting this behaviour.

Krill are not passive particles and can take advantage of different current velocities at different depths (Hofmann \& Murphy 2004). Krill are also exceptionally strong swimmers (Kils 1981, Hamner \& Hamner 2000) and reach maximum speeds (up to $15 \mathrm{~cm} \mathrm{~s}^{-1}$ ) that are faster than the currents they commonly encounter $\left(\sim 3 \mathrm{~cm} \mathrm{~s}^{-1}\right.$; Webb et al. 1998). Krill can adopt different types of swimming behaviour when searching or feeding, and these can increase or decrease the likelihood of staying in an area. There is some evidence that krill swim slower and turn more often in areas of high food concentration, while swimming faster and turning less often in areas of low food concentration (Hamner et al. 1983, Price 1989, Strand \& Hamner 1990) - a phenomenon also observed in other animals (Bell 1957). While a few studies have looked at the advective transport of krill (Hofmann \& Lascara 2000, Fach et al. 2002), none have considered how state-based behavioural decisions may alter interactions with currents.

We used a stochastic dynamic programming model (SDP) to predict the occurrence of DVM, horizontal migration and swarming and their consequences on the distribution of krill close to South Georgia. SDP models are appropriate for understanding the trade-off between the contrasting selective forces acting on the decision making of consumers (McNamara \& Houston 1986, Houston et al. 1988, Mangel \& Clark 1988, Clark \& Mangel 2000). These models predict optimal choices as a function of the state of the individual, time and the environment. Considering that krill at South Georgia face a number of contrasting conditions and that a choice to move to a different depth or density of swarm can greatly affect both their likely energetic input and risk of predation, an SDP model is perfectly suited as a technique for predicting their short-term behaviour in the region.

\section{MATERIALS AND METHODS}

We focused on the region north of Bird Island, South Georgia (Fig. 1); this area was chosen because krill Euphausia superba predators dominate in the region, particularly macaroni penguins Eudyptes chrysolophus and Antarctic fur seals Arctocephalus gazella. There are 3 zones in the model: (1) on-shore, (2) shelfbreak and (3) off-shore. These regions are biologically significant because they differ in phytoplankton concentrations (Korb et al. 2004), current velocities (Brandon et al. 2000, Atkinson et al. 2001) and predator concentrations (Hunt et al. 1992). The latitudinal boundaries for the 3 zones relate to the bathymetry around South Georgia, with the shelf-break between 500 and $2000 \mathrm{~m}$ depth.

There are 2 sections to the methods. First, we describe a simple particle movement model of krill advection, the results of which are required for the 


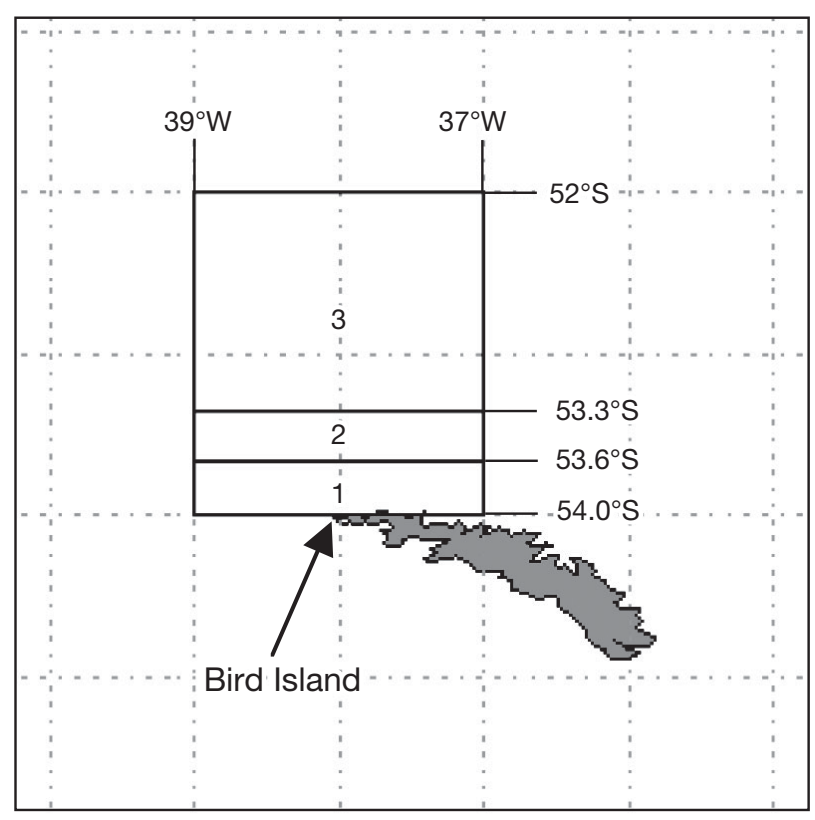

Fig. 1. Map of South Georgia with Bird Island and model zones at the NW tip: on-shelf (1), shelf-break (2) and offshelf (3). Latitude and longitude of boundaries are also given

main SDP model. We then describe the parameters and the SDP model itself.

The particle movement model. The swimming speed of krill is mainly within the range of 0 to $15 \mathrm{~cm}$ $\mathrm{s}^{-1}$, or 0 to $0.54 \mathrm{~km} \mathrm{~h}^{-1}$ (Kils 1981). There is evidence that krill slow their swimming speed and turn more often in favourable areas, such as areas of high food concentration (Strand \& Hamner 1990). Conversely, there is evidence that krill swim faster with a lower rate of turning in unfavourable areas (Price 1989). We designed a particle movement model to calculate the probability of krill being retained in or dispersing from an area given 3 different types of swimming behaviour: (1) swimming slowly and turning more often, (2) swimming quickly and turning less often, and (3) swimming at a random speed and turn rate (Fig. 2).

In the particle movement model, we randomly seeded krill onto the landscape, with krill then moving for a series of ten 6 min time steps according to the rules of swimming behaviour defined above. We added the vector from their swimming behaviour to that of the water current, which differed for region and depth, and recorded whether the krill moved from one zone to another, or out of bounds, within the hour. This was repeated 10000 times to give a total number, and therefore allowed us to compute $P_{\mathrm{m}}(d, a, z, y)$ such that:

$P_{\mathrm{m}}(d, a, z, y)=\operatorname{Pr}$ (a krill moves from zone $z$ to zone $y$ in $1 \mathrm{~h}$ given the depth $d$ and swimming behaviour a)

where $z=1,2$, or 3 and $y=1,2,3$, or $4(y=4$ signifies movement out of bounds of the defined model area).

The krill SDP model. Parameters: A list of the parameters used in the model is provided in Table 1. The fitness function $F(e, z, t \mid l)$ in the model relates linearly to the energy state of individual krill. Decisions in dynamic programming models represent a compromise between conflicting goals: to maximise energy gain $e$ and to minimise respiration costs $R(l, s)$ and mortality $\beta$. We calculated fitness at each time step $t$ of $1 \mathrm{~h}$ for krill of 30 and $50 \mathrm{~mm}$ total length (TL), the modal size frequencies at South Georgia in January 2002 and 2003 (Tarling et al. 2006). Size in the model does not change with ingested energy, and is therefore not a dynamic state. The time step of $1 \mathrm{~h}$ is based on the assumption that krill make major behavioural decisions, to migrate or feed, at scales in the order of hours, rather than minutes or seconds. This is reasonable
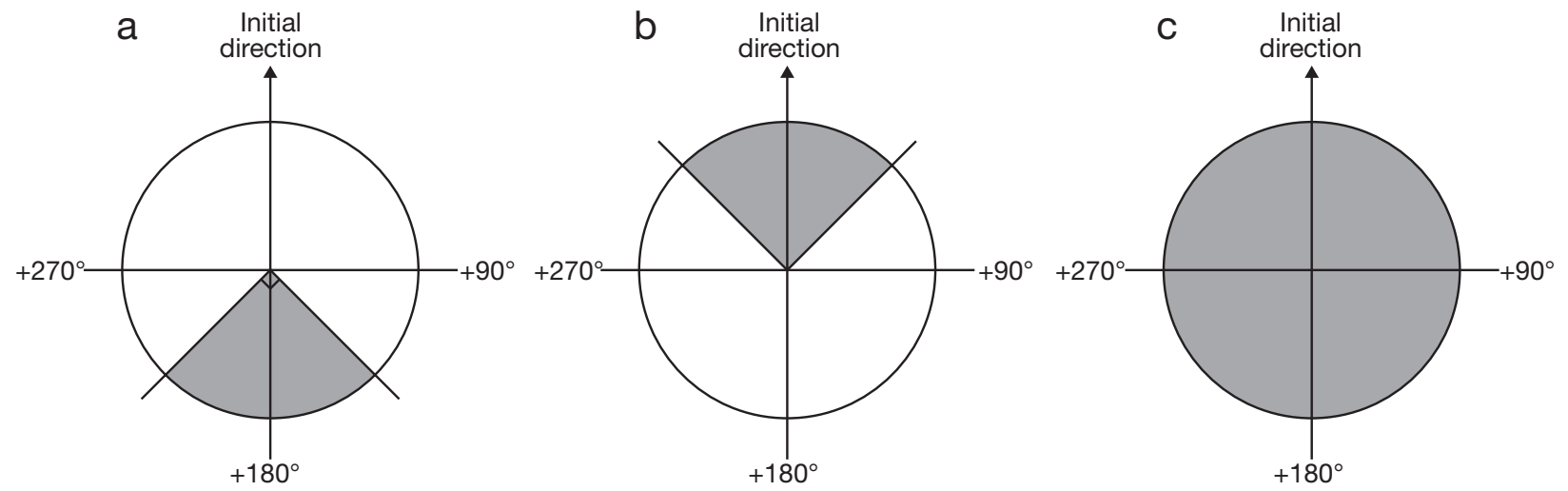

Fig. 2. Euphausia superba. The 3 types of swimming behaviour assumed by the model. The arrow represents direction in the present time step and the shaded area the range of possible directions in the following time step. (a) A swimming behaviour that increases the likelihood of retention in an area, with the speed of the new swimming vector randomly chosen from the lower half of the speed range. (b) The likelihood of dispersal from an area, with the new swimming speed randomly chosen from the upper half of the speed range. (c) A swimming behaviour whereby krill swim at a random speed with a random turn rate 
Table 1. List of parameters used in the model

\begin{tabular}{|c|c|c|c|}
\hline Symbol & Parameter & Value & Unit \\
\hline$F(e, z, t \mid l)$ & Fitness at each discrete time step & 0 to 200 & - \\
\hline$F(e, z, T \mid l)$ & Terminal fitness reward & 0 to 200 & - \\
\hline$i$ & $\begin{array}{l}\text { Behavioural decisions made by individual } \\
\text { krill at each time step }\end{array}$ & 1 to 18 & - \\
\hline$T$ & Final time step & 1500 & $\mathrm{~h}$ \\
\hline$t$ & Time step & 1 & $\mathrm{~h}$ \\
\hline$L$ & Time of day & 1 day or 2 night & - \\
\hline$d$ & Krill depth & 1 shallow or 2 deep & - \\
\hline$S$ & Swarm density, low to high & 1 to 3 & - \\
\hline a & Swimming speed and turn rate & 1 to 3 & - \\
\hline$z$ & Zone, relative to the continental shelf & 1 to 3 & - \\
\hline$y$ & Zone moved to from $z$ & 1 to 4 & - \\
\hline e & Accumulated energy & 0 to 200 & $\mathrm{mg} \mathrm{C}$ \\
\hline 1 & Size class based on total length (TL) & Small 30, large 50 & $\mathrm{~mm}$ \\
\hline$\gamma(l)$ & Target growth rate & Small 0.2, large 0.1 & $\mathrm{~mm} \mathrm{~d}^{-1}$ \\
\hline$Y(l)$ & Wet weight, based on TL & Small 209, large 1046 & $\mathrm{mg}$ \\
\hline$W(l)$ & Dry weight, based on TL & Small 45, large 226 & $\mathrm{mg}$ \\
\hline$C(1)$ & Carbon weight, based on TL & Small 19, large 101 & \\
\hline$\psi(d, z)$ & Concentration of chlorophyll & $2<\psi<160$ & $\mathrm{mg} \mathrm{C} \mathrm{m} \mathrm{m}^{-3}$ \\
\hline$\phi(s, l)$ & Filtration rate of phytoplankton & Small 0.001, large 0.002 & $\mathrm{mg} \mathrm{C} \mathrm{h}^{-1}$ \\
\hline$g(s)$ & Filtration reduced by factor with krill density & 0.1 to 1 & - \\
\hline$x$ & Assimilated ingested energy & $3 \times 10^{-6}<x<0.005$ & $\mathrm{mg} \mathrm{C} \mathrm{h} \mathrm{h}^{-1}$ \\
\hline$R(1, s)$ & Respiration & $0.01<R(1, s)<0.05$ & $\mathrm{mg} \mathrm{C} \mathrm{h} \mathrm{h}^{-1}$ \\
\hline$q(s)$ & Respiration decreases by factor with density & 0 to 0.2 & - \\
\hline$R_{f}$ & Respiration increases by factor with ingestion & 1 to 2 & - \\
\hline$k$ & Convert $\mathrm{ml} \mathrm{O}_{2}$ to $\mathrm{mg} \mathrm{C}$ & 0.5357 & - \\
\hline$M(d, s, z, L)$ & Mortality risk & $2.5 \times 10^{-8}<M<0.285$ & Probability $\mathrm{h}^{-1}$ \\
\hline$P_{\mathrm{m}}(d, a, z, y)$ & Probability of moving between zones & $0<P_{\mathrm{m}}<0.999666$ & Probability $\mathrm{h}^{-1}$ \\
\hline$\varepsilon$ & Encounter rate & - & $\mathrm{h}^{-1}$ \\
\hline$\beta$ & Mortality rate for $1 \mathrm{~h}$ & - & $\mathrm{h}^{-1}$ \\
\hline$V$ & Predator velocity (based on fish) & 50 & $\mathrm{~m} \mathrm{~h}^{-1}$ \\
\hline$N$ & Predator density & 0.006 & ind. $\mathrm{m}^{-3}$ \\
\hline $\mathrm{d} t$ & Time interval & 1 & $\mathrm{~h}$ \\
\hline$\theta$ & Field of view & 0.5 & - \\
\hline$r$ & Visual range & - & $\mathrm{m}$ \\
\hline$\lambda_{0}$ & Extinction from non-chlorophyll & 0.14 & $\mathrm{~m}^{-1}$ \\
\hline$K$ & Local diffuse attenuation coefficient & 0.2615 & $\mathrm{~m}^{-1}$ \\
\hline$C$ & Local beam attenuation coefficient & $3 \times K$ & $\mathrm{~m}^{-1}$ \\
\hline$\rho$ & Light fraction lost at the surface & 0.5 & - \\
\hline$I$ & Irradiance at the surface & See Tarling et al. (2000) & $\mu \mathrm{mol} \mathrm{m} \mathrm{m}^{-2} \mathrm{~s}^{-1}$ \\
\hline$\sigma$ & Inherent contrast of krill & 0.5 & - \\
\hline$A$ & Krill cross-sectional area & 12.6 & $\mathrm{~mm}^{2}$ \\
\hline$\Delta S$ & Planktivore eye sensitivity & $3.0 \times 10^{-6}$ & $\mu \mathrm{mol} \mathrm{m} \mathrm{m}^{-2} \mathrm{~s}^{-1}$ \\
\hline
\end{tabular}

when considering that the model runs for 1 mo and decisions such as change of depth and advection into other zones would happen over a time scale greater than minutes or seconds.

The terminal reward function $F(e, z, T \mid l)$ defines the fitness reward at the final time step of the model $T$, and depends on the krill reaching a target energy level. We based the target level on observed growth rates $\gamma(1)$ of krill during summer in the South Georgia region, which Tarling et al. (2006) reported at $\gamma(1)=0.2 \mathrm{~mm} \mathrm{~d}^{-1}$ and $\gamma(2)=0.1 \mathrm{~mm} \mathrm{~d}^{-1}$ for small $(30 \mathrm{~mm})$ and large (50 mm) krill, respectively. We converted these to units of $\mathrm{mg} \mathrm{C} \mathrm{d}^{-1}$ using functions derived by Tarling et al. (2006). If an individual did not acquire the required amount of energy by the final time $T$, there was no fitness reward, otherwise fitness is equal to the total amount of $\mathrm{C}$ assimilated by time $T$. Thus:

$$
F(e, z, T \mid l)=\left\{\begin{array}{l}
0 ; e<\gamma(l) \\
e ; e \geq \gamma(l)
\end{array}\right\}
$$

For times $t<T$, we found $F(e, z, t \mid l)$ from the SDP algorithm according to:

$$
\begin{aligned}
& F(e, z, t \mid l)= \\
& \max _{i} \sum_{y=1}^{3} P_{\mathrm{m}}\left(d_{i}, a_{i}, z, y\right) \cdot(1-\beta) \cdot F\left(e_{i}, y, t+1 \mid l\right)
\end{aligned}
$$

The time frame of the model is $1500 \mathrm{~h}$, approximately 2 mo. However, we analysed results only from the mid- 
dle of the month, Hour 376 to 1125, to minimise artefacts inherent in this type of model. As the remaining time increases, the behavioural decisions become relatively insensitive to the value of $t$ and depend more on the state variables; known as stationarity (Mangel \& Clark 1988). Taking the middle section of time from the model results is useful because now the decision of the animal depends on state and fitness, not time to death, which simplifies interpretation (Mangel \& Clark 1988, Clark \& Mangel 2000). For the current model, the parameter estimations are based on the month of January, when penguins and seals are constrained to land for the breeding season (Hunt et al. 1992, Atkinson et al. 2001).

Behavioural decisions: At each time step, individual krill in the model chose a depth (shallow $[<60 \mathrm{~m}]$ or deep [60 to $150 \mathrm{~m}$ ]) based on the average diving range of the major land-based predators at Bird Island, South Georgia (Boyd \& Croxall 1992, Croxall et al. 1993). We divided the density of swarms into low $\left(<100 \mathrm{krill} \mathrm{m}^{-3}\right)$, medium (100 to $1000 \mathrm{krill} \mathrm{m}^{-3}$ ) and high (>1000 krill $\mathrm{m}^{-3}$ ), based on directly observed swarm densities (Hamner \& Hamner 2000). Model krill chose from 3 different types of swimming behaviour in terms of swimming speed and turn rate as described previously in the particle movement model (Fig. 2).

Environmental conditions and energy balance: Krill feed mainly on phytoplankton in the vicinity of South Georgia (Atkinson et al. 2001). We estimated phytoplankton concentrations, $\psi(d, z)$, from SeaWiFS data averaged over the month of January from 2000 to 2004 for each zone in the simulated area. We obtained SeaWiFS data at a resolution of $9 \mathrm{~km}$ from GES Online Visualisation and Analysis Infrastructure (GIOVANNI; available at http://reason.gsfc.nasa.gov/ Giovanni). Values were converted from mg chlorophyll $\mathrm{m}^{-3}$ (Table 2) to $\mathrm{mg} \mathrm{C}$ through multiplication by 50 (Atkinson 1996). One of our aims was to examine the effect of different levels of phytoplankton concentrations on model predictions. There was a certain amount of variability in the extent to which different zones increased or decreased in phytoplankton availability between years, which made model interpreta-

Table 2. Average shallow concentration $( \pm \mathrm{SE})$ of phytoplankton for the month of January ( $\mathrm{mg}$ chlorophyll $\mathrm{m}^{-3}$ ) for each year and averaged over each zone. Note that the values for 2000 and 2004 were used to represent years of, respectively, higher and lower than average food availability in model runs

\begin{tabular}{|lccrcc|}
\hline Zone & 2000 & 2001 & \multicolumn{2}{l}{2002} & \multicolumn{2}{l}{2003} & \multicolumn{2}{l}{2004} \\
\hline On-shelf & $2.1 \pm 0.115$ & $0.6 \pm 0.022$ & $1.8 \pm 0.103$ & $1.8 \pm 0.126$ & $1.7 \pm 0.152$ \\
Shelf-break & $3.2 \pm 0.103$ & $0.4 \pm 0.023$ & $4 \pm 0.101$ & $3.5 \pm 0.126$ & $1.6 \pm 0.152$ \\
Off-shelf & $1.4 \pm 0.103$ & $0.5 \pm 0.023$ & $6 \pm 0.102$ & $2.7 \pm 0.125$ & $0.8 \pm 0.152$ \\
\hline
\end{tabular}

tions complex. However, a comparison of the years 2000 and 2004 was particularly instructive because phytoplankton concentrations in each of the zones in 2000 were consistently higher than values in the same zones in 2004, making it a good test of the effect of universal change across all zones. Therefore, 2000 and 2004 were chosen to represent higher than average (high) and lower than average (low) years in phytoplankton availability in subsequent model runs. To obtain deep chlorophyll concentrations, we divided the surface concentrations by 20 based on in situ measurements of chlorophyll with depth from the RRS 'James Clark Ross' (R. Korb unpubl. data) from a range of sites to the northwest of South Georgia (53.5 to $53^{\circ} \mathrm{S}, 37$ to $38^{\circ} \mathrm{W}$ ).

Hofmann \& Lascara (2000) give conversions between wet, dry and carbon weights, and equations for filtration and respiration. Filtration rate $\phi(s, 1)$ depends on dry weight $W(l)$ and swarm density $s$. We derived a scaling factor $g(s)$ based on Morris et al. (1983), where $g(1)=1$ for a low-density swarm, $g(2)=0.5$ for a medium-density swarm and $g(3)=0.1$ for a high-density swarm. Accordingly, we modified the filtration rate function described in Hofmann \& Lascara (2000) as follows:

$$
\phi(s, l)=\left[\left\{0.000143 \cdot[W(1)]^{0.514}\right\}\right] \cdot g(s)
$$

Assuming an assimilation rate of $80 \%$ (Clarke \& Morris 1983) and no resource depletion, ingestion $x$ is:

$$
x=\phi(s, l) \cdot \psi(d, z) \cdot 0.8
$$

The total respiration cost for each size class is standard metabolism $R(1, s)$ plus an increase due to feeding $R_{\mathrm{f}}$ and a decrease with increasing swarm density $q(s)$. $R_{\mathrm{f}}$ increases linearly from 0 up to 1 for a percent daily ration (mg C) from 0 to $10 \%$, remaining at 1 for a daily ration $>10 \%$ (Hofmann \& Lascara 2000). Thus, the total respiration is:

$$
R(1, s)=\left[\left\{8.47 \times 10^{-4} \cdot[W(1)]^{0.85}\right\} \cdot k \cdot q(s)\right] \cdot\left(1+R_{f}\right)(5)
$$

where $k$ is the conversion factor, from $\mathrm{ml} \mathrm{O}_{2}$ to $\mathrm{mg} \mathrm{C}$, set at 0.5357 (Hofmann \& Lascara 2000). However, there are other ways to derive this value, and we tested a $k$ of 0.4217 in the sensitivity analysis. This is based on a conversion of $46 \mathrm{~J}$ $\mathrm{mg}^{-1}$ organic C (Salonen et al. 1976) and $19.4 \mathrm{~J} \mathrm{ml}^{-1} \mathrm{O}_{2}$ respired (Elliot \& Davidson 1975). Values for the scaling of respiration with swarm density $q(s)$ (1 for a low-density swarm, 0.8 for a medium-density swarm and 0.6 for a 
high-density swarm) are based on experiments of mysids and fish, where the proposed mechanism of reduced respiration costs with increased swarm density would be provided by the hydrodynamic advantages of swimming alongside a neighbour (Parker 1975, Ritz 2000).

Mortality: In the model, 4 factors contribute to mortality $M(d, s, z, L)$ : depth $d$, density $s$, zone $z$ and time of day $L$. Average mortality, which gives the probability of death per hour, or $\bar{M}=0.0011399$, is taken from Murphy \& Reid (2001), who derived this value from net hauls taken in the vicinity of South Georgia. For average mortality we assumed that krill were in a mediumdensity swarm $(s=2)$ in the shelf-break zone $(z=2)$ with a consistent DVM. The assumed DVM places krill in a deep habitat for the illuminated two-thirds of the $24 \mathrm{~h}$ day and throughout the water column at night.

We assumed that $M(d, S, z, L)$ can be written as a linear additive model:

$$
M(d, s, z, L)=\frac{10^{\alpha}}{1+10^{\alpha}}
$$

For $\bar{M}$ we set:

$$
\bar{\alpha}=\log _{10}\left[\frac{\bar{M}}{1-\bar{M}}\right]
$$

and we scaled $\alpha$ for depth, zone, time of day and swarm density by:

$$
\alpha=\bar{\alpha}+\alpha_{d, L}+\alpha_{s}+\alpha_{z}
$$

where $\alpha_{d, L}, \alpha_{s}$ and $\alpha_{z}$ represent a relative mortality from a particular habitat choice compared to average mortality. We now explain these scalings in detail.

The parameter $\alpha_{z}$ is the distance from the central foraging place $z_{\text {; }}$ it affects mortality, with $\alpha_{z}$ decreasing with increasing distance from shore (Table 3). Previous studies during summer at Bird Island, South Georgia show a decrease in the density of both fur seals and macaroni penguins with increasing distance from the island (Hunt et al. 1992), as would be expected from

Table 3. Euphausia superba. Scaling of mortality in relation to habitat components (see Eq. 8)

\begin{tabular}{|llc|}
\hline Component & Symbol & Value \\
\hline Day shallow & $\alpha_{d, L}(d=1, L=1)$ & 2.9 \\
Day deep & $\alpha_{d, L}(d=2, L=1)$ & -2.5 \\
Night shallow & $\alpha_{d, L}(d=1, L=2)$ & 0.9 \\
Night deep & $\alpha_{d, L}(d=2, L=2)$ & -6 \\
Swarm density 1 & $\alpha_{s}(s=1)$ & 0.3 \\
Swarm density 2 & $\alpha_{s}(s=2)$ & 0 \\
Swarm density 3 & $\alpha_{s}(s=3)$ & -0.3 \\
On-shelf & $\alpha_{z}(z=1)$ & 0.5 \\
Shelf-break & $\alpha_{z}(z=2)$ & 0 \\
Off-shelf & $\alpha_{z}(z=3)$ & -0.5 \\
\hline
\end{tabular}

central place foragers (Houston \& McNamara 1985). The results from Hunt et al. (1992) indicate that predators are 10 times more concentrated on-shelf compared to off-shelf, so we used this estimation for the best estimate parameterisation of the model. We also tested a smaller and larger effect of zone habitat on mortality in the sensitivity analysis.

The parameter $\alpha_{s}$ affects mortality, where $\alpha_{s}$ increases with decreasing swarm density (Table 3). We assumed that krill in higher density swarms reduce their risk of mortality through increased vigilance and group avoidance strategies plus evasion and dilution factors once under attack (Ritz 2000). These strategies are effective against visual predators that predate krill individually, such as penguins and seals. Sensitivity analyses test the influence of swarming factors on mortality risk and krill behaviour.

For the parameter $\alpha_{d, L}$ we used the method of Fiksen \& Giske (1995) to calculate mortality for different habitats depending on depth and time of day.

To calculate mortality for different depth and time habitats, with zone and swarm density habitats at their average values $(z=2, s=2)$, we first calculated the encounter rate $\varepsilon$. This specifies the expectation that a krill will encounter a predator and depends on the visual range $r$, speed $v$, and density $N$ of the predator and the size of the prey (Eggers 1977, Tarling et al. 2000), such that:

$$
\varepsilon=\theta \pi^{2} v N \mathrm{~d} t
$$

where $\theta$ is the field of view of the predator and $\mathrm{d} t$ is the time interval, in this case $1 \mathrm{~h}$. We assumed that each encounter resulted in death of the krill, giving the expectation of mortality:

$$
M(d, 2,2, L)=1-\exp (-\varepsilon \mathrm{d} t)
$$

The local diffuse attenuation coefficient $K$ is derived from the concentration of chlorophyll $\psi(d, z)(K=$ $2.5 \mathrm{mg} \mathrm{m}^{-3}$ at South Georgia) and extinction due to non-chlorophyll particles $\lambda_{0}$ such that:

$$
K=\lambda_{0}+0.054 \cdot \psi(d, z)^{0.667}+0.0088 \psi(d, z)
$$

We then determined predator visual range $r$ using a Newton-Raphson iteration (Fiksen \& Giske 1995), such that:

$$
r^{2} \exp (C r+d K)=\rho I|\sigma| A \Delta S^{-1}
$$

where $I$ is irradiance at the surface, $\rho$ is the fraction of light lost at the surface, $K$ the diffuse attenuation coefficient, $C$ is the beam attenuation coefficient giving the turbidity, $d$ is depth (here $<60$ or 60 to $150 \mathrm{~m}$ ), $A$ is the krill cross-sectional area, $\sigma$ is the krill inherent contrast and $\Delta S$ is the planktivore eye sensitivity threshold for prey recognition. We set the beam attenuation coefficient at $3 K$ (Fiksen \& Giske 1995). 
We solved the encounter rate $\rho$ for the above equations at every $5 \mathrm{~m}$ depth interval from 5 to $150 \mathrm{~m}$ for each hour of the day and night using light intensity values parameterised for a light regime similar to that of the study region (Tarling et al. 2000), the average latitude of the study region. We then found an average expectation of mortality from the above method, assuming a stable DVM and an average swarm density $(s=2)$ and zone $(z=2)$, and matched this to $\bar{M}=$ 0.0011399 (Murphy \& Reid 2001) by adjusting predator density $N$. This resulted in a predator density of $N=$ $0.0006 \mathrm{~m}^{-3}$ near South Georgia.

With the newly calculated predator density value, we then obtained values for $\alpha_{d, L}$ by comparing the habitat-specific values (i.e. day shallow, day deep, night shallow, night deep) of mortality to average mortality $\bar{M}$.

Running the model. The dynamic programming algorithm works backward in time to calculate the optimal policy for each level of the state variables of the individual and for each time (Mangel \& Clark 1988, Clark \& Mangel 2000). The optimal policy specifies an action or decision that maximises fitness for each state $(d, s$, or $z)$ for different size classes of krill at each time. Moving forward through the time steps, an individual with an initial set of state parameters effectively has a

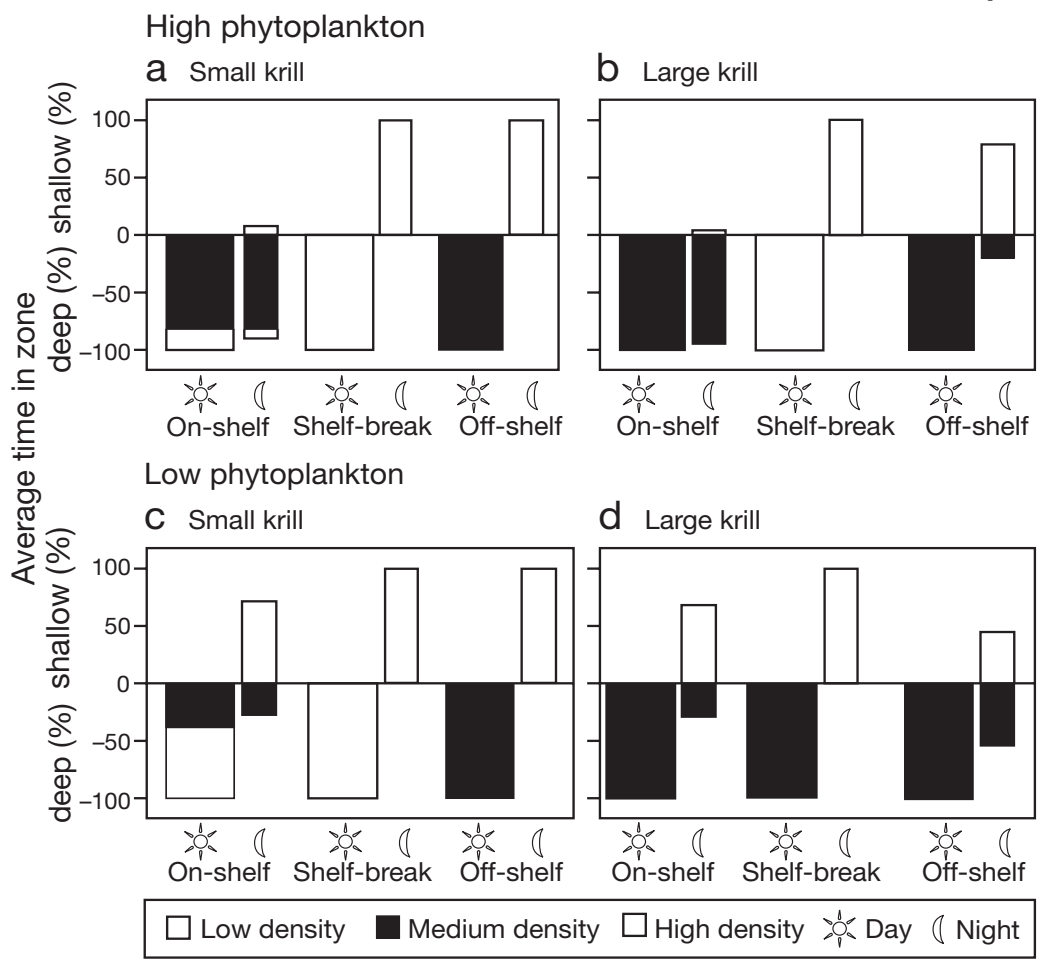

Fig. 3. Euphausia superba. The predicted average depth and density of small $(30 \mathrm{~mm})$ and large $(50 \mathrm{~mm})$ krill, for day and night in each of the zones, and for simulations of both high (avg. $2.23 \mathrm{mg}$ chlorophyll $\mathrm{m}^{-3}$ ) and low (avg. $1.4 \mathrm{mg}$ chlorophyll $\mathrm{m}^{-3}$ ) phytoplankton availability (Table 2). Medium density was predicted not to occur map of the optimal decisions to make at each time step, which will further affect its state and fitness and therefore the decision chosen at the following time step. Adding stochasticity varies the behavioural routine between individuals over time, even though the individuals are following the same optimal policy.

Model runs. Terminal rewards: We ran the model first with the best-estimate parameters (Table 1) but with different functions for the terminal reward to determine how much of an effect this would have on the results. For the terminal reward, we tested 3 scenarios. We described Terminal Reward 1 (TR1) previously (Eq. 1). For Terminal Reward 2 (TR2), fitness at the final time is proportional to accumulated energy, as follows:

$$
F(e, z, T \mid 1)=e
$$

By contrast, fitness at the final time with Terminal Reward 3 (TR3) was zero:

$$
F(e, z, T \mid 1)=0
$$

However, the fitness accrues each time step with ingested energy $x_{i}$ such that:

$$
\begin{aligned}
& F(e, z, t \mid l)= \\
& \max _{i} \sum_{y=1}^{3} P_{\mathrm{m}}\left(d_{i}, a_{i}, z, y\right) \cdot\left(1-\beta_{i}\right) \cdot\left[F\left(e_{i}, y, t+1 \mid l\right)+X_{i}\right]
\end{aligned}
$$

Sensitivity: Finally, we conducted a sensitivity test of 5 parameters, chosen either because of their likely influence on model predictions or because a lack of data made it difficult to specify values for a particular parameter. The 5 parameters tested were $\psi(d, z), q(s), k$ and 2 factors affecting mortality: zone $z$ and swarm density $s$. Each model run was carried out for both small (30 mm) and large $(50 \mathrm{~mm}) \mathrm{krill}$ and for situations where the availability of food $\psi(d, z)$ was either high or low (see years 2004 and 2001 respectively in Table 2).

\section{RESULTS}

\section{Predicted behaviour}

The DVM and swarm-density pattern for krill Euphausia superba throughout regions and simulated food concentrations differed in the model with best estimates of parameters (Fig. 3). Krill were predicted always to be deep during the day, mostly in high-density swarms, except in the 
shelf-break and on-shelf regions, where we predicted deep, low-density swarms. At night, krill were predicted to form shallow, low-density swarms, except most krill on the shelf with high food availability and large krill off the shelf with low food availability, which form deep, high-density swarms at night. For each region and size, we generally predicted a lower swarm density in low-food simulations compared to under high-food conditions. Similarly, small krill were predicted to form a higher proportion of dispersed and shallow swarms, a more risky behaviour, than large krill in most situations.

An alternative way to look at the krill depth and density behaviour is to examine the average number of krill adopting a particular behaviour at each time step (Fig. 4). Overall, we predicted that more krill form deep, high-density swarms when food availability is low, probably because these krill are able to save energy by forming a higher density swarm. In addition, we predicted that a large number of krill will disperse when food availability is high because the benefit of feeding in a low-density swarm outweighs the increased predation risk.

We also predicted the behaviour of krill in terms of swimming speed and turn rate, affecting the likelihood of retention within an area. With high phytoplankton availability, both small and large krill were predicted to adopt a swimming behaviour that increases the probability of dispersing away from the on-shelf and off-shelf zones, but maximises the probability of retention in the shelfbreak zone (Fig. 5). With low food availability, the predicted krill behaviour in the shelf-break and off-shelf zones is the same as with high food availability. However, the swimming behaviour was predicted to differ on the shelf, with most large krill ( $\sim 70 \%)$ and some small krill $(\sim 10 \%)$ adopting a swimming behaviour that increases the probability of staying in the zone as opposed to the dispersal-type behaviour observed when food availability was high. We predicted that no krill swim with a random speed and turn rate for either high or low phytoplankton availability.

\section{Predicted distribution of krill}

Krill concentration ( $\mathrm{krill} \mathrm{m}^{-2}$ ) was calculated by dividing the total number of krill in a region by the total area $\left(\mathrm{m}^{2}\right)$ of the region. These figures represent a nominal scale to be treated in a relative fashion, not as a measure of the real concentrations expected in the field.

The number of krill in all regions declined over time within the season (Fig. 6). Krill were constantly diffusing out of the model area, after which they no longer

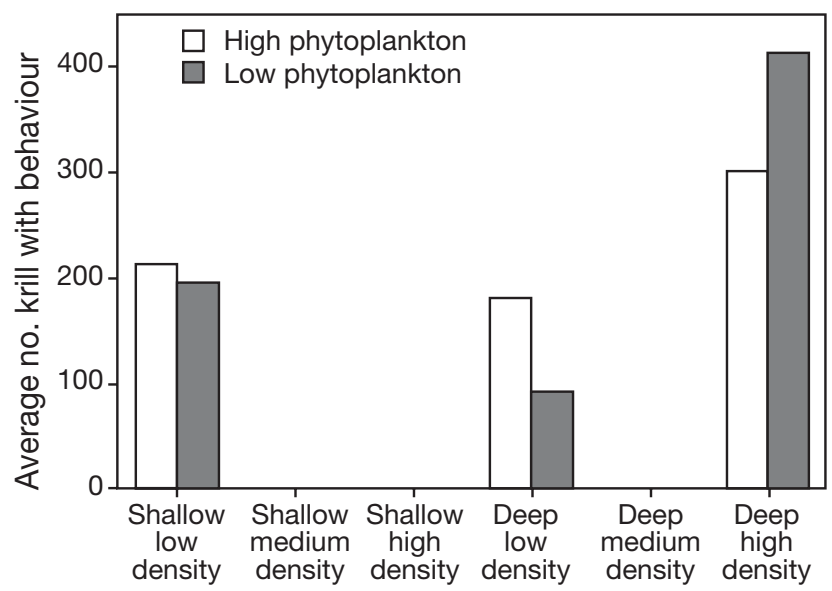

Fig. 4. Euphausia superba. Behaviours adopted by krill, in terms of depth and density, with average number of krill adopting behaviour per time step for low and high (values as listed for Fig. 3) phytoplankton availability

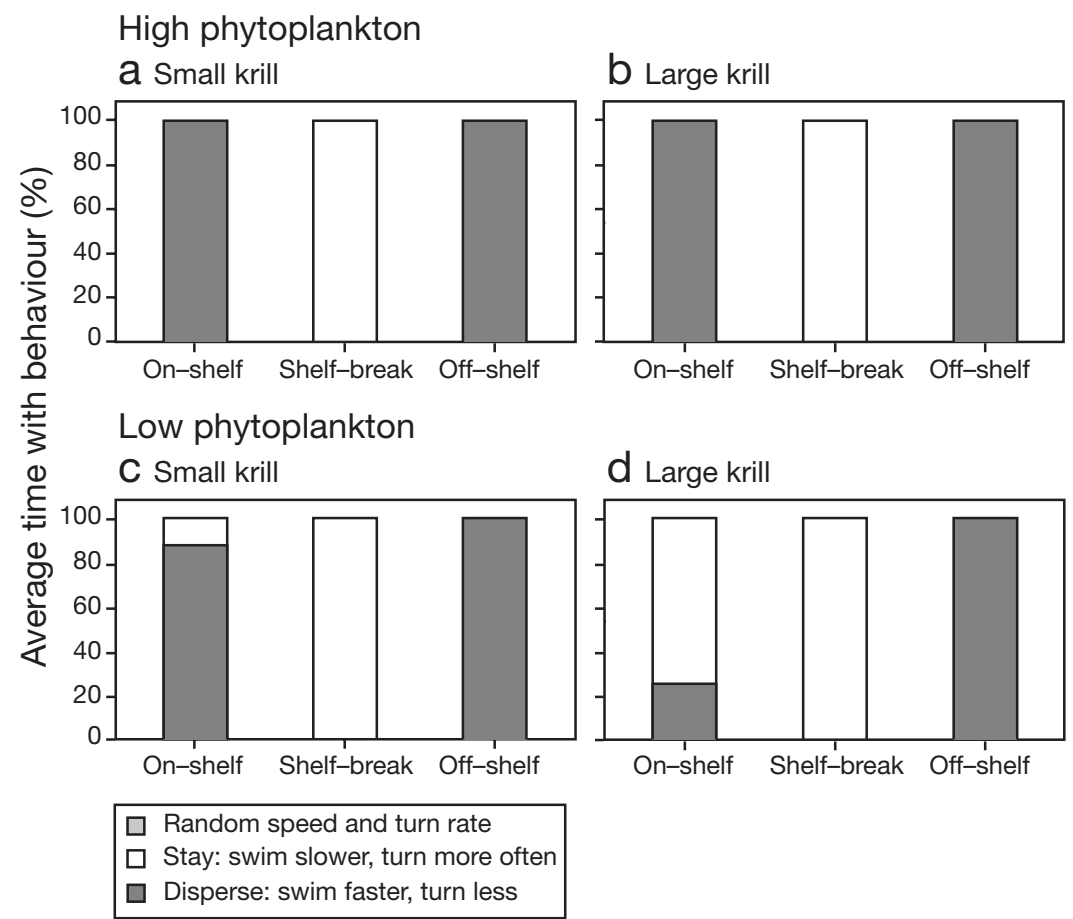

Fig. 5. Euphausia superba. Swimming behaviour of small $(30 \mathrm{~mm})$ and large $(50 \mathrm{~mm}) \mathrm{krill}$ in terms of swimming speed and turn rate, according to rules for random swimming, swimming to stay in zone and swimming to disperse from zone. Results are averaged from simulations with high and low (values as listed for Fig. 3) phytoplankton availability. Random speed and turn rate were predicted not to occur 


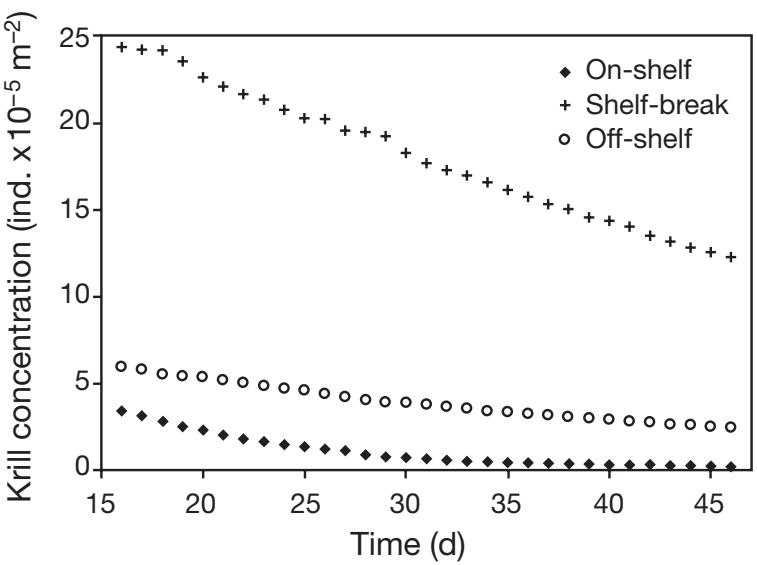

Fig. 6. Euphausia superba. The concentration $\left(10^{-5}\right.$ ind. $\left.\mathrm{m}^{-2}\right)$ of large $(50 \mathrm{~mm})$ krill over time, for a simulation with high phyto-plankton availability (as listed for Fig. 3)

counted in the results and did not have an opportunity to re-enter the region that we modelled. Krill were not removed from the model by mortality and were not added to the model region after the initial starting time. This effect of krill diffusing from the model area commenced on model Day 1, which explains why concentrations on Day 15 were already unequal. It was also clear that this effect was not as strong at the shelfbreak as in the other 2 regions, so that, by the end of the simulation, concentrations at the shelf-break were comparatively high.

On Day 46, krill concentration was consistently at least 4 times greater in the shelf-break than off-shelf zone and at least 10 times higher than in the on-shelf zone (Fig. 7). We predicted that large krill are more likely than small krill to stay on the shelf when food availability is low.

\section{Terminal reward}

We tested 3 scenarios for the terminal reward: TR1, with target growth rates; TR2, where fitness at the final time is proportional to accumulated energy, with no target growth rate; and TR3, where fitness at the final time is zero for all states, but the dynamic programming algorithm is modified so the fitness accrues with ingested energy during each time step. Overall, changing the terminal reward did not change the overall predictions of the model, but it did alter the results slightly $(\sim 5 \%)$. We predicted the most risky behaviour for a model with TR2. In this scenario, a greater proportion of krill ( $5 \%$ more than TR1) were predicted to form shallow, low-density swarms and a swimming behaviour that leads to accumulation in the highest mortality zone: on the shelf. Risky behaviour was predicted for this scenario probably because fitness is highly influenced by ingestion during each time step, meaning that there is a relatively high cost if the krill does not eat for a whole time step. By contrast, we found the behaviour in a model with TR3 to be the least risky, with a greater proportion of deep, high-density swarms $(\sim 5 \%$ more than TR1) leading to a lower final energy state. Here, krill do not need to reach a threshold energy level in order to obtain a fitness reward, in comparison to TR1, and therefore do not need to work as hard, particularly in challenging conditions such as low food availability on the shelf. The difference between the terminal reward predictions was most noticeable under low-food, high-mortality conditions (on-shelf).
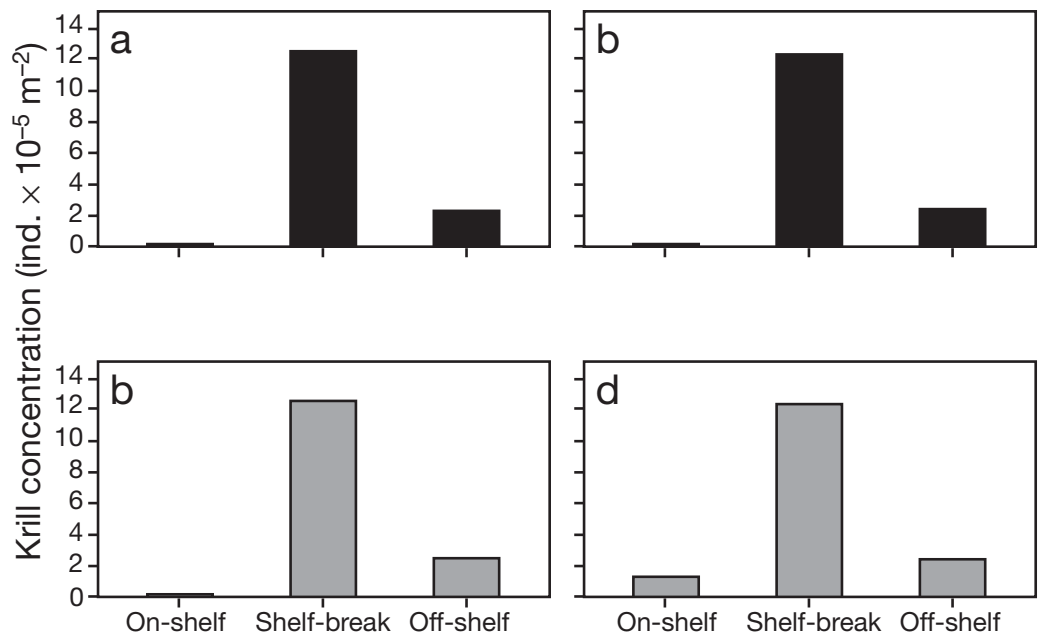

Fig. 7. Euphausia superba. Final krill concentration in each of the zones for $(\mathrm{a}, \mathrm{c})$ small $(30 \mathrm{~mm})$ and $(\mathrm{b}, \mathrm{d})$ large $(50 \mathrm{~mm})$ krill, and simulations $(\mathrm{a}, \mathrm{b})$ high and $(\mathrm{c}, \mathrm{d})$ low phytoplankton availability (values as listed for Fig. 3)

\section{Sensitivity analysis}

We calculated sensitivity by dividing the percentage change in the result of interest by the percentage change in the parameter value, such that:

$$
\text { Sensivity }=\frac{\Delta \text { result } \%}{\Delta \text { parameter } \%}
$$

Generally, the results were most sensitive to changes in the parameters defining respiration and food availability (Table 4). The final energy level of krill, predicted depth and density of swarm were most sensitive to changes in respiration, while the final concentration of krill in each of the zones was most sensitive to changes in food availability and mortality relating to distance from the island. 
Table 4. Relative sensitivity of the model results to variation in each of the main model parameters. Bold values indicate where the results were most sensitive. $\mathrm{x}=$ sensitivity 0 to $0.5, \mathrm{xx}=$ sensitivity 0.5 to $1, \mathrm{xxx}=$ sensitivity 1 to 2 , $\operatorname{xxxx}=$ sensitivity 2 to 5 , and $\mathrm{xxxxx}=$ sensitivity $>5$ (DVM: diel vertical migration of zooplankton)

\begin{tabular}{|c|c|c|c|c|c|}
\hline Result & $\begin{array}{l}\text { Food conc. } \\
\qquad(d, z)\end{array}$ & $\begin{array}{l}\text { Respiration } \\
\text { conversion } k\end{array}$ & $\begin{array}{l}\text { Respiration } \\
\text { (swarm) } q(s)\end{array}$ & $\begin{array}{l}\text { Mortality } \\
\text { (zone) } \alpha_{z}\end{array}$ & $\begin{array}{l}\text { Mortality } \\
\text { (swarm) } \alpha_{s}\end{array}$ \\
\hline Energy & $\mathrm{xxx}$ & $\mathbf{x x x x}$ & $\operatorname{xxxx}$ & $\mathrm{xx}$ & $\mathrm{xx}$ \\
\hline \multicolumn{6}{|l|}{ Krill concentration } \\
\hline On-shelf & $\mathbf{x x x x x}$ & $\mathrm{xxxx}$ & $\mathrm{xxx}$ & $\operatorname{xxxxx}$ & $\mathrm{xx}$ \\
\hline Shelf-break & $\mathbf{x}$ & $\mathrm{x}$ & $\mathrm{x}$ & $\mathrm{x}$ & $\mathrm{x}$ \\
\hline Off-shelf & $\mathrm{x}$ & $\mathrm{xx}$ & $\mathrm{xx}$ & $\mathbf{x x}$ & $\mathrm{x}$ \\
\hline DVM & $\mathrm{x}$ & $\mathbf{x x}$ & $\mathrm{xx}$ & $\mathrm{x}$ & $\mathrm{x}$ \\
\hline $\begin{array}{l}\text { Low-density } \\
\text { swarm }\end{array}$ & $\mathrm{xxxx}$ & $\operatorname{xxxxx}$ & $\mathbf{x x x x x}$ & $\mathrm{xxxx}$ & $\mathrm{xxx}$ \\
\hline $\begin{array}{l}\text { Medium-density } \\
\text { swarm }\end{array}$ & y & $\mathbf{x x}$ & $\mathrm{xx}$ & $\mathrm{x}$ & $\mathrm{xx}$ \\
\hline $\begin{array}{l}\text { High-density } \\
\text { swarm }\end{array}$ & $\mathrm{x}$ & $\mathbf{x x}$ & $\mathrm{xx}$ & $\mathrm{x}$ & $\mathrm{x}$ \\
\hline
\end{tabular}

\section{DISCUSSION}

The main findings of the model are that: (1) krill Euphausia superba were able to change their concentration in an area without knowing where they were going, but simply by changing their swimming speed and turn rate; (2) overall krill concentration is predicted to be highest at the shelf-break for both lowand high-availability food years; (3) a diel pattern in swarm density is an evolved behaviour; and (4) large krill are predicted to be found in denser swarms on the shelf than small krill, due to differences in the trade-off between mortality and food intake.

\section{DVM at South Georgia}

Most krill in the model exhibited a classic DVM, migrating downwards during the day and upwards during the night, with some exceptions. For simulations with high and low food concentrations, we predict that both small and large individual krill will consistently be deep during the day. However, predicted depth at night is more variable. We predict krill to be shallow at night, on-shelf with low-availability food conditions, but deep with high-availability food conditions. Because of the high concentration of food onshelf, small and large krill were still able to reach their target growth rates even if they were deep at night, a behaviour that effectively minimised the risk of predation in a high-risk region. Off-shelf, we predict variations to the DVM pattern, but only for large krill. A proportion of large krill off-shelf are predicted to form deep, high-density swarms at night, more so when food availability is low. This suggests that large krill maximise fitness by lowering their respiration costs in this low-food region. Small krill are predicted to adopt a DVM in the same region (off-shelf), perhaps because they are under more pressure to reach target growth rates or because the cost of respiration in shallow, low-density swarms does not outweigh the benefit of feeding.

The occurrence of a classic DVM pattern (for both freshwater and oceanic zooplankton) is believed to represent a trade-off between maximising food intake in the shallow water and minimising predation risk in the deep (Cuvier 1817, Russell 1927). However, a variety of patterns in vertical migration have been reported for krill (Everson 1983, Godlewska 1996, Hays 2003). Reverse migration (i.e. upward migration during the day and deeper at night) is a type of migration that is usually associated with high levels of either invertebrate predators that use tactile stimuli or predators that feed in the deep (Verity \& Smetacek 1996, Hays 2003). This type of migration has been observed at South Georgia (Kalinowski 1978, Godlewska 1996). Other authors have reported that the depth and migrational amplitude of DVM changes in proportion to the concentration of chlorophyll in an area (Godlewska 1996). This is apparent in the model, with a higher proportion of krill adopting a deep habitat in simulations with higher food concentrations.

\section{Diel differences in swarming}

We predict deep, high-density swarms during the day for small and large krill in nearly all simulations and shallow, low-density swarms at night in most simulations. Medium-density swarms are not predicted for the model with best estimate parameters. Deep, highdensity swarms occurred during the day because krill could save energy and minimise high predation rates with this behaviour. Alternatively, the consistent prediction of deep, high-density swarms during the day could be an artefact of the scaling of mortality, with scaling due to time of day or swarm density being too extreme. Low-density swarms occurred at night simply because krill were at the surface to feed on higher concentrations of phytoplankton when mortality from diving predators was reduced, and dispersing at this time maximised their food intake. The contrary prediction of deep, high-density swarms at night for a proportion of small and large krill on-shelf suggests that predator avoidance in this instance is more important than 
energy intake. The prediction of this behaviour in offshelf areas probably reflects the fact that energetic gain in the shallow water was so low that saving energy and minimising mortality in deep, high-density swarms accrued higher fitness.

While the occurrence of a classic DVM pattern is well known, there has been less work on diel patterns in swarming. There is some evidence that krill can be found in shallow and dispersed swarms at night, reforming into deep, high-density swarms during the day (Witek et al. 1981), but there has been little experimental work. Studies indicate that krill disperse in the shallow water to feed, sinking and forming swarms to save energy and decrease mortality risk at the point of satiation (Witek et al. 1981, Godlewska 1996). Even in the present model, completely different swarm densities could be found for different krill in the same area due to slight changes in the trade-off balance between feeding and predator avoidance. Overall, we predict that a change in the parameterisation of respiration is the most important factor affecting swarm density, more important than factors relating to mortality, which highlights a need for more laboratory work in this area.

\section{Size-dependent swarming behaviour}

We predict different behaviours for small and large krill in some zones during the day. On the shelf, we predict a small proportion of small krill forms deep, low-density swarms during daylight hours, but large krill in all zones form deep, high-density swarms. The difference in behaviour on the shelf suggests that the trade-off between energy intake and predator avoidance is slightly different for small and large krill. Offshelf, the difference was obvious at night, where small krill are always predicted to be shallow in low-density swarms, but a proportion of large krill are predicted to be deep in high-density swarms. High-density swarms at night occurred in the model because large krill in deep water could maximise their fitness from the energy saved combined with the reduced mortality of being in a high-density swarm. Low-density swarms at night may have occurred because small krill were under more pressure than large krill to feed, or because small krill had lower respiration costs than large krill.

There are a number of reasons why krill of different sizes may adopt particular swarm densities in the field. First, small krill filter phytoplankton from the water at a much lower per-animal rate than large krill (Hofmann \& Lascara 2000), but their weight-specific growth rates during January at South Georgia are up to twice that of large krill (Atkinson et al. 2006). Thus, there could be a greater demand for lower density swarms, where food can be filtered more efficiently. Second, large krill could potentially maximise fitness by the energy saved combined with the reduced mortality of being in a high-density swarm, compared to the increased respiration and mortality associated with feeding in shallow waters in a low-density swarm, particularly under low-availability food conditions. This is based on the idea that krill can save energy in higher density swarms due to hydrodynamic effects. Indeed, there is evidence that krill sink and re-form into schools after feeding in shallow waters (Godlewska 1996, Tarling et al. 2000) and that in deep water they swim slower in school formation (Zhou \& Dorland 2004), which would allow further savings of energy (Swadling et al. 2005), although the latter evidence comes from a study that took place in the autumn and does not relate speed to food concentration. In the model, however, krill could not save energy by swimming slower because respiration did not depend on swimming speed. In the field, small krill may be less detectable and less preferred by diving predators (Hill et al. 1996, Reid et al. 1996). A size-dependent mortality function may be a useful addition to future parameterisations of the present model.

\section{Krill influencing their position}

Krill in the model were able to increase or decrease their likelihood of staying in an area by changing their swimming speed and turn rate. However, there was little evidence for krill altering their depth to change their location. Areas in the model that ended up with the highest concentrations of krill were areas where krill chose to swim slowly and turn more often. Areas that ended up with the lowest concentrations of krill were areas where krill chose to swim more quickly and turn less often. We predict that the final concentration of krill in an area is most sensitive to the abundance of phytoplankton and changes in mortality relating to distance from the island. The highest overall concentration of krill is predicted at the shelf-break for all sizes and simulations of varying food levels.

High concentrations of krill have been associated with areas of water turbulence, often coinciding with high phytoplankton concentrations, such as eddies, fronts and at the shelf-break (Witek et al. 1981, Hunt et al. 1992, Godlewska 1996, Trathan et al. 2003). In addition, there are generally higher concentrations of krill on-shelf than off-shelf, although this is not always the case (Hunt et al. 1992, Siegel 2000). Some researchers believe krill are passively advected to certain regions where they concentrate (Hofmann \& Lascara 2000, Fach et al. 2002), but the degree to which processes other than advective transport influence the observed Antarctic krill distribution are relatively unknown (Hof- 
mann \& Murphy 2004). For example, some authors suggest that krill, as a swarm, can sense gradients in phytoplankton and temperature and can therefore locate and move to more favourable areas of higher phytoplankton concentration (Grunbaum 1998). In this way, krill may behave as a 'super' organism. Krill in the model were able to increase their concentration in favourable areas without 'knowing' where they were going, or without the currents directing them to these areas, but simply by having a lower swimming speed with a higher turn rate in favourable areas and a higher swimming speed with a lower turn rate in unfavourable areas.

On a smaller scale, there has been some experimental work into the swimming behaviour of krill in favourable and unfavourable areas (Price 1989), but little work to examine how this behaviour would affect the distribution of swimming krill in combination with currents in a given area (Zhou \& Dorland 2004). Vertical migration of krill can also affect their horizontal distribution, if surface and deep currents are significantly different (Hofmann \& Murphy 2004). This has been shown for other species (Hardy 1936, Rogers 1940, Emsley et al. 2005). Although some authors suggest the krill are unlikely to use this to change their position (Hays 2003), it is possible that krill have evolved variations in the amplitude of the DVM in response to currents impacting their distributions.

\section{Size-dependent trends in krill concentration}

Low levels of phytoplankton resulted in large krill being about 4 times more concentrated than small krill on-shelf. We predict that the difference in concentration for small and large krill in this situation is due to a difference in swimming behaviour, with all large krill choosing a swimming behaviour that maximised the probability of staying on-shelf, and a proportion of small krill choosing a behaviour that increased dispersal from the region. Underlying the different choice in swimming behaviour is a difference in the trade-off between mortality and feeding for small and large krill. In a low phytoplankton year, there wasn't sufficient food in any of the zones for large krill to meet their growth rates, but the phytoplankton concentration was highest on-shelf. Here, both mortality and phytoplankton abundances were higher than in any other region, but large krill could reduce mortality rates by adopting a stable DVM pattern, and they maximised food intake at night by dispersing. Small krill could still reach their target growth rates on the shelf, but their fitness was maximal at the shelf-break, where phytoplankton was less available, but predation was comparatively reduced.
Differences in the behaviour of small and large krill have been observed regarding the vertical distribution of krill in the water column (Godlewska 1996), but there has been less work on size differences in horizontal distribution. In general, smaller krill are found to the east of South Georgia and larger krill to the west. This is most likely because young krill are transported from the Antarctic Peninsula and grow on their journey, which takes them first to the eastern end of South Georgia and then along the northern side to the west (Atkinson et al. 2001, Fach et al. 2002). This assumes that krill are passive particles that do not affect their own distribution. At the South Shetland Islands, krill in nets appeared to show distinct offshore-inshore differences in abundance and maturity stages (Ichii et al. 1998). At the South Orkney Islands, small juvenile and immature krill occurred east of the islands, adult krill $<50 \mathrm{~mm}$ dominated the shelf areas of the Antarctic Peninsula and krill $>50 \mathrm{~mm}$ occurred west of the islands (Siegel et al. 2004). In addition, in the region of the Antarctic Peninsula, one study found mainly gravid females in the Drake Passage, smaller krill in the Weddell Sea and juvenile/adolescent male krill on the shelf (Witek et al. 1981).

\section{At the shelf-break}

The behaviour of krill at the shelf-break in simulations of low and high phytoplankton availability made them more vulnerable to predation than in other regions. Krill are predicted to choose a swimming behaviour that results in a large increase in concentration in the region, at least 5 times higher than any other region, making them more available to predators. This behaviour is a result of the favourable balance between mortality and food intake in this region, particularly when food availability is high. The resulting large difference between krill concentration at the shelf-break and in other regions may partly be the result of the extreme difference in mortality between zones. In addition, this finding may be significantly influenced by a change in the relative availability of phytoplankton in each of the zones, which influences the relative favourability of each of the zones in terms of food intake and mortality risk.

With high food availability, we predict low-density swarms day and night for all krill at the shelf-break, again increasing their vulnerability to predators. This behaviour did not occur with low food availability, perhaps because the cost of increased mortality and respiration from forming deep, low-density swarms outweighed the benefit of maximising feeding in deep water. However, we predict that krill will not swarm densely, but will perform a DVM in this environment 
as their main strategy of reducing predation. We stress the importance of knowing both depth and density of krill with changing conditions because both are equally important in terms of their availability to predators and to the krill fishery.

While there is some evidence that krill are found in higher concentrations at the shelf-break (Witek et al. 1981, Trathan et al. 1998), the reasons behind this trend are not well understood. Here we predict that krill accumulate in this region to exploit the higher primary productivity at a lower risk than feeding on-shelf. To achieve this, krill only have to exhibit a simple turning response and change swimming speed according to food availability.

Acknowledgements. This work is part of a PhD thesis through the British Antarctic Survey (BAS) and Open University, funded through the National Environmental Research Council and contributing to the FLEXICON project of the DISCOVERY 2010 programme at BAS. The latter stages of this research were supported by the Lenfest Ocean Program. Thanks to P. Trathan for help and support throughout, S. Thorpe for data on currents in the region, B. Korb for information on phytoplankton, A. Atkinson and J. Watkins for continuous help with krill conceptual problems, and M. Mangel for time and input in the final stages.

\section{LITERATURE CITED}

Atkinson A (1996) Subantarctic copepods in an oceanic, low chlorophyll environment: ciliate predation, food selectivity and impact on prey populations. Mar Ecol Prog Ser 130: 85-96

Atkinson A, Whitehouse MJ, Priddle J, Cripps GC, Ward P, Brandon MA (2001) South Georgia, Antarctica: a productive, cold water, pelagic ecosystem. Mar Ecol Prog Ser 216: 279-308

Atkinson A, Shreeve R, Hirst AG, Rothery Pand 5 others (2006) Natural growth rates in Antarctic krill (Euphausia superba). II. Predictive models based on food, temperature, body length, sex and maturity stage. Limnol Oceanogr 51: 973-987

Bell WJ (1957) Searching behaviour. The ecology of finding resources. Chapman and Hall, London

Boyd IL, Croxall JP (1992) Diving behavior of lactating Antarctic fur seals. Can J Zool 70:919-928

Brandon MA, Murphy EJ, Trathan PN, Bone DG (2000) Physical oceanographic conditions to the northwest of the subAntarctic Island of South Georgia. J Geophys Res C105: 23983-23996

Burrows MT, Tarling G (2004) Effects of density dependence on diel vertical migration of populations of northern krill: a genetic algorithm model. Mar Ecol Prog Ser 277:209-220

Clark CW, Mangel M (2000) Dynamic state variable models in ecology. Oxford University Press, Oxford

Clarke A, Morris DJ (1983) Towards an energy budget for krill-the physiology and biochemistry of Euphausia superba Dana. Polar Biol 2:69-86

Croxall JP, Briggs DR, Kato A, Naito Y, Watanuki Y, Williams TD (1993) Diving pattern and performance in the macaroni penguin Eudyptes chrysolophus. J Zool 230:31-47

Croxall JP, Reid K, Prince PA (1999) Diet, provisioning and productivity responses of marine predators to differences in availability of Antarctic krill. Mar Ecol Prog Ser 177: $115-131$

Cuvier G (1817) La regne animale, Vol 2. Deterville, Paris

De Robertis A (2002) Size-dependent visual predation risk and the timing of vertical migration: an optimization model. Limnol Oceanogr 47:925-933

Eggers DM (1977) Planktivore preference by prey size. Ecology 77:46-59

Elliot JM, Davidson W (1975) Energy equivalents of oxygen consumption in animal energetics. Oecologia 19:195-201

Emsley SM, Tarling GA, Burrows MT (2005) The effect of vertical migration strategy on retention and dispersion in the Irish Sea during spring-summer. Fish Oceanogr 14: 161-174

Everson I (1983) Variations in vertical distribution and density of krill swarms in the vicinity of South Georgia. In: Nemoto T, Matsuda T (eds) Proceedings of the BIOMASS Colloquium in 1982. National Institute of Polar Research, Tokyo, p 84-92

Everson I, Goss C (1991) Krill fishing activity in the southwest Atlantic. Antarct Sci 3:351-358

Fach BA, Hofmann EE, Murphy EJ (2002) Modeling studies of antarctic krill Euphausia superba survival during transport across the Scotia Sea. Mar Ecol Prog Ser 231:187-203

Fiksen O, Giske J (1995) Vertical-distribution and population-dynamics of copepods by dynamic optimization. ICES J Mar Sci 52:483-503

Godlewska M (1996) Vertical migrations of krill (Euphausia superba Dana). Pol Arch Hydrobiol 43:9-63

Grunbaum D (1998) Schooling as a strategy for taxis in a noisy environment. Evol Ecol 12:503-522

Hamner WM, Hamner PP (2000) Behavior of Antarctic krill (Euphausia superba): schooling, foraging, and antipredatory behavior. Can J Fish Aquat Sci 57:192-202

Hamner WM, Hamner PP, Strand SW, Gilmer RW (1983) Behavior of Antarctic krill, Euphausia superba - chemoreception, feeding, schooling, and molting. Science 220: $433-435$

Hardy AC (1936) Plankton ecology and the hypothesis of animal exclusion. Proc Linn Soc Lond 148:64-70

Hays GC (2003) A review of the adaptive significance and ecosystem consequences of zooplankton diel vertical migrations. Hydrobiologia 503:163-170

Hill HJ, Trathan PN, Croxall JP, Watkins JL (1996) A comparison of Antarctic krill Euphausia superba caught by nets and taken by macaroni penguins Eudyptes chrysolophus: Evidence for selection? Mar Ecol Prog Ser 140:1-11

Hofmann EE, Lascara CM (2000) Modeling the growth dynamics of Antarctic krill Euphausia superba. Mar Ecol Prog Ser 194:219-231

Hofmann EE, Murphy EJ (2004) Advection, krill, and Antarctic marine ecosystems. Antarct Sci 16:487-499

Houston AI, McNamara JM (1985) A general-theory of central place foraging for single-prey loaders. Theor Pop Biol 28: 233-262

Houston A, Clark C, McNamara J, Mangel M (1988) Dynamicmodels in behavioral and evolutionary ecology. Nature 332: 29-34

Hunt GL, Heinemann D, Everson I (1992) Distributions and predator-prey interactions of macaroni penguins, Antarctic fur seals, and Antarctic krill near Bird Island, South Georgia. Mar Ecol Prog Ser 86:15-30

Ichii T, Katayama K, Obitsu N, Ishii H, Naganobu M (1998) Occurrence of Antarctic krill (Euphausia superba) concentrations in the vicinity of the South Shetland Islands: relationship to environmental parameters. Deep-Sea Res I 45: $1235-1262$ 
Iwasa Y (1982) Vertical migration of zooplankton - a game between predator and prey. Am Nat 120:171-180

Kalinowski J (1978) Vertical migration of krill in the region of South Georgia, February-March 1976. Pol Arch Hydrobiol 25:573-583

Kils U (1981) The swimming behaviour, swimming performance and energy balance of Antarctic krill, Euphausia superba. BIOMASS Scientific Series 3:1-121

Korb KE, Whitehouse MJ, Ward P (2004) SeaWiFS in the southern ocean: spatial and temporal variability in phytoplankton biomass around South Georgia. Deep-Sea Res II 51: 99-116

Mangel M, Clark C (1988) Dynamic modeling in behavioral ecology. Princeton University Press, Princeton, NJ

Mangel M, Nicol S (2000) Krill and the unity of biology. Can J Fish Aquat Sci 57:1-5

Mangel M, Switzer PV (1998) A model at the level of the foraging trip for the indirect effects of krill (Euphausia superba) fisheries on krill predators. Ecol Model 105:235-256

Marr JWS (1962) The natural history and geography of the Antarctic krill (Euphausia superba Dana). Disc Rep 32: 33-464

McNamara JM, Houston AI (1986) The common currency for behavioral decisions. Am Nat 127:358-378

Morris DJ, Ward P, Clarke A (1983) Some aspects of feeding in the Antarctic krill, Euphausia superba. Polar Biol 2:21-26

Murphy EJ, Reid K (2001) Modelling Southern Ocean krill population dynamics: biological processes generating fluctuations in the South Georgia ecosystem. Mar Ecol Prog Ser 217:175-189

Nicol S (2006) Krill, currents, sea ice: Euphausia superba and its changing environment. Bioscience 56:111-120

O'Brien DP (1987) Description of escape responses of krill (Crustacea, Euphausiacea), with particular reference to swarming behavior and the size and proximity of the predator. J Crustac Biol 7:449-457

Parker FR (1975) Reduced metabolic rates in fishes as a result of induced schooling. Trans Am Fish Soc 1:125-131

Price HJ (1989) Swimming behavior of krill in response to algal patches - a mesocosm study. Limnol Oceanogr 34: 649-659

Quetin LB, Ross RM, Clarke A (1994) Krill energetics: seasonal and environmental aspects of the physiology of Euphausia superba. In: El-Sayed SZ (ed) Southern Ocean ecology: the BIOMASS perspective. Cambridge University Press, Cambridge, p 165-184

Reid K, Trathan PN, Croxall JP, Hill HJ (1996) Krill caught by predators and nets: differences between species and techniques. Mar Ecol Prog Ser 140:13-20

Ritz DA (2000) Is social aggregation in aquatic crustaceans a strategy to conserve energy? Can J Fish Aquat Sci 57:59-67

Rogers HM (1940) Occurrence and retention of plankton within the estuary. J Fish Res Board Can 5:164-171
Russell FS (1927) The vertical distribution of plankton in the sea. Biol Rev 2:213-262

Salonen K, Sarvala J, Hakala I, Viljanen ML (1976) The relation of energy and organic carbon in aquatic invertebrates. Limnol Oceanogr 21:724-730

Siegel V (2000) Krill (Euphausiacea) demography and variability in abundance and distribution. Can J Fish Aquat Sci 57 151-167

Siegel V, Kawaguchi S, Ward P, Litvinov F, Sushin V, Loeb V, Watkins J (2004) Krill demography and large-scale distribution in the southwest Atlantic during January/February 2000. Deep-Sea Res II 51:1253-1273

Strand SW, Hamner WM (1990) Schooling behavior of Antarctic krill (Euphausia superba) in laboratory aquaria: reactions to chemical and visual stimuli. Mar Biol 106: 355-359

Swadling KM, Ritz DA, Nicol S, Osborn JE, Gurney LJ (2005) Respiration rate and cost of swimming for Antarctic krill, Euphausia superba, in large groups in the laboratory. Mar Biol 146:1169-1175

Tarling G, Burrows M, Matthews J, Saborowski R, Buchholz F, Bedo A, Mayzaud P (2000) An optimisation model of the diel vertical migration of northern krill (Meganyctiphanes norvegica) in the Clyde Sea and the Kattegat. Can J Fish Aquat Sci 57:38-50

Tarling G, Shreeve RS, Hirst AG, Atkinson A, Pond D, Murphy EJ, Watkins J (2006) Natural growth rates in Antarctic krill (Euphausia superba). I. Improving methodology and predicting intermoult period. Limnol Oceanogr 51(2): 959-972

Trathan PN, Murphy EJ, Croxall JP, Everson I (1998) Use of at-sea distribution data to derive potential foraging ranges of macaroni penguins during the breeding season. Mar Ecol Prog Ser 169:263-275

Trathan PN, Brierley AS, Brandon MA, Bone DG, Goss C, Grant SA, Murphy EJ, Watkins JL (2003) Oceanographic variability and changes in Antarctic krill (Euphausia superba) abundance at South Georgia. Fish Oceanogr 12: 569-583

Verity PG, Smetacek V (1996) Organism life cycles, predation, and the structure of marine pelagic ecosystems. Mar Ecol Prog Ser 130:277-293

Webb DJ, de Cuevas BA, Coward AC (1998) The first main run of the OCCAM global ocean model. Internal document no. 34, Southampton Oceanography Centre, Southampton, UK

Witek Z, Kalinowski J, Grelowski A, Wolnomiejski N (1981) Studies of aggregations of krill (Euphausia superba). Meeresforschung 28:228-243

Zhou M, Dorland RD (2004) Aggregation and vertical migration behavior of Euphausia superba. Deep-Sea Res II 51: $2119-2137$

Submitted: August 2, 2006; Accepted: January 31, 2007

Proofs received from author(s): July 6, 2007
Editorial responsibility: Otto Kinne (Editor-in-Chief), Oldendorf/Luhe, Germany 